International

Medical Society

http://imedicalsociety.org

\title{
Influence of Low Back Pain in the Functional Capacity of Older People
}

Ana Paula Vieira de Lucena1, Dannielle Santiago de Souza Leão Fernandes ${ }^{2}$, Elicarlos Marques Nunes ${ }^{3}$, Juliane de Oliveira Costa Nobre ${ }^{3}$, Elvis Costa Crispiniano ${ }^{4}$, Ana Carolina Miranda Luna Marques ${ }^{2}$, Nicoly Negreiros de Siqueira Mariano ${ }^{5}$, Vandezita Dantas de Medeiros Mazzaro5,

Adriano Moura de Menezes Dantas ${ }^{5}$, Samara Campos de Assis ${ }^{4}$, Celio Diniz Machado Neto ${ }^{4}$, Manuela Carla de Souza Lima Daltro ${ }^{4}$, Jamili Anbar Torquato ${ }^{6}$

\section{Abstract}

Introduction: The lumbar pain is a set of painful manifestations that reach the lower back and sacroiliac, manifested in both sexes and all age groups, but increases dramatically with age, it is regarded as an important cause of disability, ranging from acute, subacute and chronic pain.

Objective: This study aimed to investigate the influence of lumbar pain in the functional capacity of elderly residents in the city of Cajazeiras - PB.

Methodology: This is a cross-sectional study, analytical with a quantitative approach, conducted with 43 elderly patients with lumbar pain attended at the elderly pastoral meetings of St John Bosco church in the city of Cajazeiras - PB. It was used as a collection tool a questionnaire with socio demographic data, the visual analogue scale (VAS) and the Roland-Morris disability questionnaire. Data analysis was performed using the computer program SPSS version 20.0, and analyzed using descriptive and inferential statistics.

Results: It was observed that most of the elderly were female, widowed, illiterate and predominant age group being 71-82 years old. The pain was classified as intense (39.53\%) for most of the sample and through the Roland-Morris was established that all participants showed some degree of disability, and (62.6\%) had severe disability.
1 Student's undergraduate in physical therapy from Santa Maria School, Cajazeiras - PB, Brazil.

2 Physiotherapists. Teacher in Santa Maria School, Cajazeiras - PB, Brazil.

3 Nurses. Department of Nursing of Patos Integrated College, Patos (PB), Brazil.

4 Physiotherapists. Department of Physical Therapy of Patos Integrated College, Patos (PB), Brazil.

5 Doctors. Department of Medicine of the Patos Integrated College, Patos (PB), Brazil.

6 Physiotherapist. Teacher of the University Cruzeiro do Sul, Brazil.

\section{Contact information:}

Elicarlos Marques Nunes.

Address: Wanderley Bossuet Street, apt 521. 101. Neighborhood: Center.

CEP: 58700-410 - Patos (PB), Brazil.

” elicarlosnunes@yahoo.com.br 
Conclusion: Through this study it was found that low back pain generates significant influence on the functional capacity of the elderly, it is important to develop actions aimed to health promoting and preventing and consequently improving the quality of life of this age group.

\section{Keywords}

Lumbar Pain; Disability; Elderly.

\section{Introduction}

Aging is an inevitable process to be alive, it is characterized by a series of biological changes outlined for each species, which translates into a decrease in behavioral plasticity, evolutionary decline and therefore increased vulnerability and probability of death [1].

Aging leads complex demands and requires special attention, not meaning to say that it is a disease, but rather a stage of life with its own characteristics, where changes occur both organically as metabolic nature. Such changes generate imbalance in immunity and in functional mechanisms of these individuals, causing changes in emotional, intellectual and communication conditions [2]. The World Health Organization (WHO) defines elderly as any individual with equivalent age of 60 years or more for those who live in developing countries and 65 or more for individuals in developed countries [3].

The growth of the elderly population as a worldwide phenomenon is a topic widely studied today, since this growth is proposed to confirm the projections of (WHO) that provides for the year 2025, 30 million of seniors, thus corresponding to $10 \%$ of the population. This estimate of (WHO), will lead Brazil to occupy the sixth position among the nations with the highest number of elderly [4].

Each year about 650 thousand of elderly people are added to the brazilian population, where most of these presents with chronic diseases and some have functional limitations [5]. Chronic disease is dominant and is implicated as a major cause of disability, particularly in the elderly. The prevalence of functional disability in the Brazilian population is greater in older women and further increases with advancing age [6]. Among the chronic diseases, we can mention the lumbar pain.

The functional capacity ( $F C$ ) is the ability that the elderly have to correspond the daily physical demands, which ranges from basic activities for independent living up to the toughest everyday actions. It has been observed in old age a decrease in the levels of (FC) due to the decline in physical function as: reducing in the functionality of musculoskeletal, cardiorespiratory and nervous systems, condition that may impair the elderly to perform their routine tasks efficiently [7].

The lumbar pains affect about $80 \%$ of the population, generating a high cost for the health and welfare due to the large number of withdrawal and inability to work caused by this disease [8]. It is considered as an important cause of disability, ranging from acute, subacute and chronic pain, the latter being considered when pain persists for more than 12 weeks [1].

The lumbar pain or low back pain is defined as a set of painful manifestations that affect the lumbar, lumbosacral or the sacroiliac region. These manifestations are among the most frequently submitted by individuals and can be triggered by various conditions including: high workload, traumatic or degenerative processes in the discs or vertebral body, obesity, smoking, excessive movement, among others. Low back pain is a health condition that may cause significant limitations in people's lives [9]. 
This type of disease is a disorder that manifests itself in both sexes, is seen as a major cause of disability, presents with high prevalence in industrialized countries, and in all age groups, but increases dramatically with age, appearing mainly in individuals over 65 years of age [1].

Low back pain presents as the main symptom pain accompanied by reduced range of motion, appearance of muscle spasms, decreased muscle strength and postural changes [10]. Patients with low back pain constantly demonstrate difficulties to pick up objects on the floor, up and down stairs and walking, been common notice in these individuals a reduction in sports and social activities [9]. Knowing that is the most likely age group to develop diseases that can lead to disability, the present study described the attention to this age group by checking which impacts the low back pain may result in functional independence of it, and through that knowledge led actions towards real need of the group and offers a share of contribution to the health sciences. In this perspective this study aimed to investigate the influence of low back pain in the functional capacity of elderly residents in the city of Cajazeiras - PB, Brazil.

\section{Methodology}

It is a cross-sectional and analytical study, with a quantitative approach, performed in the parish hall of St. John Bosco Church in the city of Cajazeiras PB, Brazil, during the month of April 2013.

The study included 43 elderly of both sexes aged over 60 years with back pain complaints, attended by the pastoral care of elderly and perform physical activity with a physical educator once a week for 30 minutes in the parish hall.

The sample size was calculated using the statistical method of BERNI where the error margin was 10\%. According Berni [11] the sample non-random techniques generally attempt to generate samples that somehow represents reasonably well the population from which they were extracted.
Inclusion criteria were to have: aged 60 years or more, of both sexes, have complaints of low back pain for at least one month in addition to good cognitive understanding and hearing to respond to the questionnaires.

The participants were evaluated through questionnaires, they are: socio-demographic questionnaire prepared by the researcher, composed of open and closed questions such as: name, age, sex, marital status, educational level, who they live with, it is drug use, occupation and family income. The functional disability questionnaire Roland-Morris (QIRM) and visual analogue scale (VAS).

The functional disability questionnaire RolandMorris (QIRM) is used to assess chronic pain in the form of self-reported for patients with back pain, and to compare and evaluate the treatment and the evolution of these patients, it is necessary to have an instrument that quantify the limitations induced for the low back pain. The questions have a dichotomous response (yes or no) and the end result is the sum of yes answers. This result can vary between 0 and 24, corresponding zero to a person without complaints and the maximum value in a patient with very severe limitation.

The QIRM was validated in 12 languages and adapted to other populations of patients with pain in the spine, it is a reliable method, fast and easy to analyze and calculate an average it takes 5 minutes to administer. Studies have demonstrated validity and reliability to the Brazilian translation [12].

The questions of (QIRM) are quite simple, on physical disability, and for each affirmative answer gives it a score of " 1 " and " 0 " for each question that the patient does not agree. The score of this questionnaire is the sum of values, where the closer the maximum score, the greater is the disability. The cutoff point of the Morris Rolland is the score 14, i.e., evaluated persons which have more than 14 are considered with disability [13]. The visual analogue scale is a scale similar to a rule that serves to analyze the intensity of back pain, is numbered 1-10, where 0 means no pain and 10 severe pain [8]. 
After the project was approved by the Research Ethics Committee (REC) of the Santa Maria School, in the opinion ( ${ }^{\circ}$ 253112), data collection was carried out both in the parish hall, where the weekly meetings happen as in the homes of participants.

It was initially made contact with the Elderly Church's Pastoral of St. John Bosco of Cajazeiras/ $\mathrm{PB}$, where the group is registered in order to request the release for this study. After being granted permission to the realization of the research, a visit to the elderly group was carried out, the researcher has proposed development of research, then was scheduled a meeting with the seniors who agreed to participate.

At the time of interview all seniors signed the consent form and clarified (IC) and soon after reported the intensity of their pain by marking a line at the point of (EVA) which represented the pain in the lumbar spine, then answered the questionnaire of socio-demographic data and later the Roland Morris Disability.

Data were recorded in the form of computer program database SPSS (Statistical Package for Social Sciences) Statistics for Windows, version 20.0, and analyzed using descriptive and inferential statistics. For descriptive procedures, it was presented the absolute and relative data (frequencies and percentages) and measures of central tendency (mean) and variability (standard deviation, minimum and maximum limits and confidence intervals). The procedures of statistical inference, in turn, were carried out by simple linear regression analysis, predicting the scores on the criterion variable and using confidence limits.

It is noteworthy that such analysis disregards a normal distribution, and for that, it was performed the Kolmogorov-Smirnov test, confirming the normality of the data. Finally, for the interpretation of the information it was adopted at the 95\% confidence interval and a significance level of $5 \%$ ( $p$ $<0.05)$.

The study followed the ethical and legal aspects of Resolution 196/96 of the National Health Council regarding research involving human subjects [14].

\section{Results}

Participated in this study 43 elderly, mostly female $(83.72 \%)$, who are aged from 60 to 70 years (46.51\%) and 71 to 82 years (53.49\%). The elderly had the marital status: single (2.33\%), married (25.58\%), widowed (65.12\%) and divorced (6.98\%). Regarding education, most had no formal education $(60.47 \%)$, with the information presented in

Table 1.

Table 1. Presentation of the sociodemographic data of the participants as to the age, gender, marital status and education .

\begin{tabular}{|c|c|c|}
\hline Variables & $f$ & $\%$ \\
\hline \multicolumn{3}{|l|}{ Age } \\
\hline $60-70$ & 20 & 46.51 \\
\hline $71-82$ & 23 & 53.49 \\
\hline \multicolumn{3}{|l|}{ Gender } \\
\hline Male & 7 & 16.28 \\
\hline Female & 36 & 83.72 \\
\hline \multicolumn{3}{|l|}{ Marital status } \\
\hline Single & 1 & 2.33 \\
\hline Married & 11 & 25.58 \\
\hline Widowed & 28 & 65.12 \\
\hline Divorced & 3 & 6.98 \\
\hline \multicolumn{3}{|l|}{ Education } \\
\hline Illiterate & 26 & 60.47 \\
\hline Incomplete Elementary & 9 & 20.93 \\
\hline Full Elementary & 3 & 6.98 \\
\hline High school & 5 & 11.63 \\
\hline Total & 43 & 100 \\
\hline \multicolumn{3}{|c|}{$f=$ frequency (number of participants) } \\
\hline & age $c$ & e sample \\
\hline
\end{tabular}


Even as the participants socio-demographic characteristics, it was found that mostly had minimum wage 01 minimum salary (30.23\%), 02 minimum salaries (41.86\%) and 03 salaries (23.26\%). Participants are retirees or pensioners, and the profession that exerted in most years worked were: domestic $(41.86 \%)$, farmers (18.60\%) and seamstresses (9.30\%), as shown in table 2 . It should be noted also that the majority lived with family (76.74\%) and make use of medicines (86.05\%), as detailed in the information (Table 2)

The participants in this study reported on the intensity of pain. With medium intensity equal to 5.84 $(S D=2.58)$, ranging from 1 to 10 . Thus, ratings were obtained: mild (30.23\%), moderate (30.23\%) and severe (39, 53\%).

Likewise, the degree of disability of the sample was evaluated and obtained average of 11.95 (SD $=5.73$ ) with the sum of the "yes" responses ranging from 2 to 23 affirmative. These responses were subjected to regression analysis to evaluate the relationship between the variables.

Prior to performing the analysis, it was applied the Kolmogorov-Smirnov test to metric variables of the study, to estimate the distribution of the data. The probabilities associated of the test ranged from 0.38 to 0.56 , which indicates a normal distribution, allowing the performing of regression analysis.

It was observed a correlation between the intensity of the pain and disability level submitted by the participants of 0.65 (moderate correlation), suggesting therefore that $42 \%$ of the variation of the first (disability) can be explained by variation in the levels of the second (pain intensity). Adjusting such percentage of variance for the population, faced with the 0.41 index, in form that, generalizing these results to the population, $41 \%$ of the disability can be predicted by the intensity of pain.

With a trust range of $95 \%$ and likely linked below 0, 001, it proves to be unlikely that the result was due to sampling error and that it is possible the calculation of the equation below. The chart
Table 2. Presentation of sociodemographic data of the participants on the family income, profession, people who live and use of medications.

\begin{tabular}{|c|c|c|}
\hline Variables & f & $\%$ \\
\hline \multicolumn{3}{|l|}{ Mensal Family Income } \\
\hline 01 minimum wage & 13 & 30.23 \\
\hline 02 minimum wages & 18 & 41.86 \\
\hline 03 minimum wages & 10 & 23.26 \\
\hline 04 minimum wages & 1 & 2.33 \\
\hline 05 minimum wages & 1 & 2.33 \\
\hline \multicolumn{3}{|l|}{ Profession } \\
\hline Farmer & 8 & 18.6 \\
\hline Home worker & 18 & 41.86 \\
\hline Seamstress & 4 & 9.3 \\
\hline Vigilant & 1 & 2.33 \\
\hline Production assistant & 1 & 2.33 \\
\hline Salesman & 1 & 2.33 \\
\hline Nursing technique & 1 & 2.33 \\
\hline Washerwoman & 1 & 2.33 \\
\hline Potter (brick/tile) & 1 & 2.33 \\
\hline Merchant & 1 & 2.33 \\
\hline Cobbler & 1 & 2.33 \\
\hline Imporvisator & 1 & 2.33 \\
\hline Carpenter & 1 & 2.33 \\
\hline Cutting and sewing professor & 1 & 2.33 \\
\hline Cook & 1 & 2.33 \\
\hline \multicolumn{3}{|l|}{ Lives with? } \\
\hline Alone & 10 & 33.26 \\
\hline Family & 33 & 76.74 \\
\hline \multicolumn{3}{|l|}{ Use of medicines } \\
\hline Yes & 37 & 86.05 \\
\hline No & 6 & 13.95 \\
\hline \multicolumn{3}{|c|}{$f=$ frequency (number of participants) } \\
\hline & age $c$ & e sample \\
\hline
\end{tabular}


Figure 1: Patient's inability assessment depending on the pain intensity.

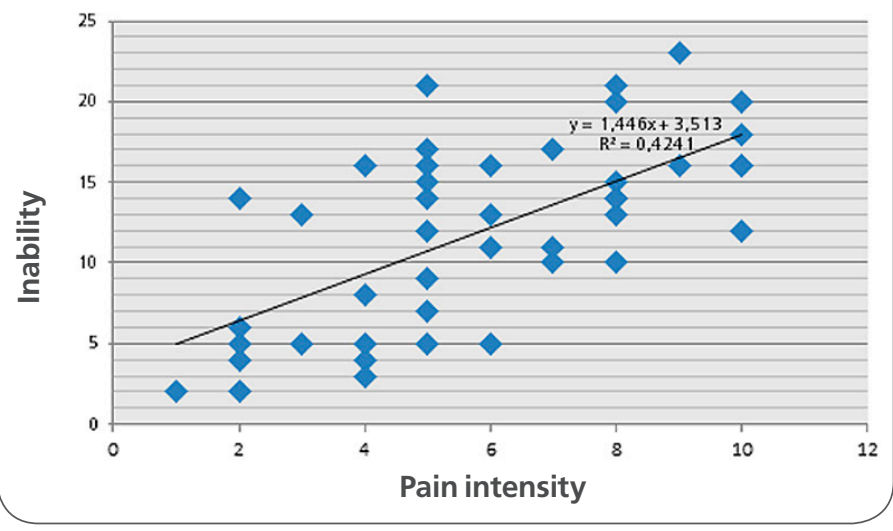

Table 3. Distribution of the domains and facets of QoL. João Pessoa, PB, 2015.

\begin{tabular}{|c|c|c|c|c|c|c|}
\hline \multirow[t]{2}{*}{$\begin{array}{c}\text { Pain } \\
\text { Intensity }\end{array}$} & \multicolumn{2}{|c|}{$\begin{array}{c}\text { Disability } \\
\text { (Up To } 14 \\
\text { Points) }\end{array}$} & \multicolumn{2}{|c|}{$\begin{array}{c}\text { Severe } \\
\text { Disability } \\
(>14)\end{array}$} & \multicolumn{2}{|c|}{ Total } \\
\hline & $f$ & $\%$ & f & $\%$ & $f$ & $\%$ \\
\hline Light & $12^{*}$ & $44.4^{\star}$ & 1 & 6.2 & 13 & 30.2 \\
\hline Moderate & 8 & 29.7 & 5 & 31.2 & 13 & 30.2 \\
\hline Intense & 7 & 25.9 & $10 *$ & $62.6^{*}$ & 17 & 39.6 \\
\hline$\chi^{2}(p)$ & \multicolumn{4}{|c|}{$8.25(0.01)$} & 43 & 100 \\
\hline & \multicolumn{6}{|c|}{$f=$ frequency (number of participants) } \\
\hline & \multicolumn{6}{|c|}{$\%=$ percentage of the sample } \\
\hline
\end{tabular}

below indicates the value of 3.51 for the equation as the slope of the line is 1.44, indicating that for each level of pain, it is increased 1.44 the inability of the patient, the variable y means the failure to be estimated and the $X$ the pain intensity, as can be seen below the graphic model (Figure 1).

For explanation purposes, follows the example. From the pain scan through the corresponding scale, it is assumed that the intensity is 5 points. Substituting this value in the equations, it is estimated that the disability is approximately 10.71 points.

In order to assess the incapacity presented by the participants according to the intensity of pain, the data have been reclassified into groups: The subjects with scores equal to or less than 14 points were classified in the group with disability, while those with a score over 14 points, were classified as having severe disability. In the same perspective, the intensity of pain was reclassified as mild (1 to 4), moderate (5 to 6) and severe (7 to 10). After this reclassification, the data were submitted to the chi-square test, which pointed to statistically significant associations. Of all the subjects with disabilities (44.4\%) had mild pain, as well as all patients who had severe disability (62.6\%) had severe pain, as shown in Table 3.

\section{Discussion}

The results found in this study about the sociodemographic characteristics of the participants, showed that in relation to gender, the studied population is comprised mostly by females (83.72\%) and $(16.28 \%)$ of male, corroborating with the study conducted by Caraviello et al [8], concerning the assessment of pain and function in patients with low back pain, found that most of the studied population was composed of women (86.7\%). The high number of females can be explained by a greater clustering of women in the population and the fact that women care more and seek health care more often. Global data show that the planet the female population presents a greater amount than the male [15].

With respect to age, participated in the study elderly aged 60 and 82, where the majority belonged to the age group of $71-82$ years (53.49) of the sample. The age range is considered an extremely important point for this population, because with the advanced age the elderly becomes more susceptible to catching diseases and therefore have a higher degree of dependence [16]. In another study it was shown that advanced age is associated with severe functional dependence [17].

The fastest growing population of elderly people today is that over the age of 70, because according to the health ministry, this age group has shown an accelerated growth, especially among those consi- 
dered elderly in the elderly age, representing today over $12 \%$ of elderly population [18].

Marital status presented by the vast majority of the elderly in this study was to widowhood, corresponding to $(65.12 \%)$ of the sample. Similar result to this was observed in a study by Telha et al, with 104 elderly, where there was a predominance of widows (49.0\%) and most of whom were female. As for widows female come forward in greater numbers, it is explained by the fact that men have a shorter life span, as well as of the widowed men marry more often after widowhood [19].

In another study it was also seen a majority of widowed about (44.7\%), with a ratio of about four times the number of women compared to men [20].

As to education, it was appointed in this study a high level of illiteracy in the elderly population (60.47\%). It is possible that poorly educated in the study population may reflect the quality of life and consequently on their health. People with a suitable level of education have a better understanding and insight into the health care and usually have better financial condition, favoring adherence to healthy habits [21].

As to the family income of the participants, can be observed that most of the elderly reported having monthly family income of 02 minimum wages corresponding to $(41.86 \%)$ of the sample, followed by a very significant percentage of 01 salary (30.23\%). These data are relevant, since the low family income may restrict their access to food, health and social care, compromising expressively the quality of life for these patients [22].

All participants in the sample are retired by age or pensioner and the profession/occupation exercised during most of the years worked and they reported were: domestic (41.86\%), farmers (18.60\%) and seamstresses $(9,30 \%)$. Studies show females as a risk factor for chronic low back pain. This can be associated with the fact that women are responsible for carrying out household chores, activities that would expose the lumbar spine to overload and repetitive strain which over time may contribute to the emergence of chronic back pain [23-24].

As for the family arrangement, it was seen that (76.74\%) of participants lived with their families. This is a positive point, because it shows the family support at this stage of their lives, which over the years had many physiological, social and emotional losts. In old age, the individual is subject in need of functional, financial or emotional support and family is still the major provider of support to the elderly [25]. The need for assistance can contribute to many older people start to live with their families and no longer live independently [26].

The use of drugs was observed in (86.05\%) of the elderly and used for multiple morbidities, among them, the most autorefered were diabetes, hypertension, pain, heart disease and osteoporosis. Result similar to this can be seen in a study for Nunes et al [27] with elderly residents in the city of Ubá- Minas Gerais, where it was found that $100 \%$ of participants used drugs and the vast majority had at least one chronic disease.

As for the data of pain intensity, our findings obtained by visual analogue scale (VAS) showed an average of 5.84 (SD = 2.58), in a range of 1 to 10. Most participants $(39,53 \%)$ rated their pain as severe. Corroborating with the results of a study conducted with individuals with chronic low back pain in the city of Jequié-BA, which (70.6\%) of participants reported intense pain through (VAS) [10]. In another study realized by Mann et al [28] showed that (50\%) of individuals with low back pain showed intense pain using the same instrument to assess pain.

As the functional ability of participants, it was observed that the average result was equal to 11.95 $(S D=5.73)$, ranging from 2 to 23 . In accordance with the findings in this study, can - be seen that the lumbar pain generates negative influence on the functional capacity of the group studied, because $(44.4 \%)$ of those presented disability, ie scored 
in response to (QIRM) to 14 points, reported mild pain and those with serious functional disability, meaning scored above 14 points (62.6\%) reported severe pain, thereby demonstrating that the increase in pain intensity, functional disability level of the individuals also increases.

Result similar to this was found by Abreu [29] in their study, which demonstrated a strong correlation between pain intensity with the degree of disability, proposing that the intensity of pain can be considered as an important tool for increasing inability the individual. On the other hand, in a correlation study of data between pain, disability and quality of life in patients with chronic lower back pain, there was no connection between pain intensity and degree of disability, because the pain and the onset of disability can be influenced by psychosocial and biomechanical factors [30].

The participants reported changes in some life habits with the onset of pain, such as staying at home more often and staying for longer in lying and sitting positions than usual, conduct the daily life tasks more slowly and with other people support, not conducting some postures as lower up or kneel, impaired appetite, sleep and mood.

According to the findings of this study, the presence of low back pain influences in the functional capacity of the elderly, present in varying degrees of limitations for all seniors in this research. There is the presence of some difficulties due to low back pain, to perform their activities of daily living fully and satisfactorily, there is a significant association $(p<0.05)$ between pain intensity and degree of disability.

\section{Conclusion}

All subjects with disabilities (44.4\%) had mild pain, as well as all patients who had severe disability (62.6\%) had severe pain.

It was found that low back pain generates significant influence on the functional capacity of the elderly, providing a negative impact on the lives of this population.

Since disability is not a permanent state but a gradual and continuous process whose evolution can be prevented, or even reduced, it is important to the continuity of existing health activities and should be the presence of other professionals, to allow practices that generate improvements in quality of life for seniors.

\section{References}

1. Silveira MM, Pasqualotti $A$, Colussi EL, Vidmar MF, Wibelinger LM, et al. Physical therapy approach to low back pain. Journal of health sciences. 2010 July/September; (25).

2. Schmidt TCG Silva MJP. Perception and understanding of health professionals and students on the elderly and human aging. Rev. esc. enferm. USP [online]. 2011; 46 (3): 612-617.

3. Mendes MRSS, Gusmao JL, Faro ACM, RCBO Leite, et al. The social situation of the elderly in Brazil: A brief consideration. Acta Paul Enferm. 2005; 18 (4): 422-6.

4. Dellaroza MSG, CAM pepper, Matsuo T. Prevalence and characterization of chronic pain in non-institutionalized elderly. Cad. Public health. 2007 May; 23 (5): 1151-1160.

5. Veras R. Population aging today: demands, challenges and innovations. Rev. Public health. 2009; 43 (3): 548-554.

6. Rabelo DF, Cardoso CM. Self-efficacy, chronic diseases and functional disability in old age. Psycho-USF, 2007 Jan./June; 12 (1): 78-81.

7. Camara FM, Gerez AG, Miranda MLJ, Velardi, et al. Functional capacity of the elderly: assessment methods and trends. Acta Fisiatra. 2008; 15 (4): 249-256.

8. Caraviello EZ, Wassertein S, Chamlian TR, Masiero D, et al. Evaluation of pain and function in patients with low back pain treated with a back school program. Acta Fisiatra, 2005; 12 (1) 11-14.

9. Ocarino JM, Gonçalves GGP, Vaz DV, Cabral AAV, Porto JV, Silva MT, et al. Correlation between functional performance questionnaire and physical impairment testing in patients with low back pain. Brazilian Journal of Physiotherapy. 2009 Jul/Aug; 13 (4): 343-349.

10. Mascarenhas CM, Santos, LS. Assessment of pain and functional capacity in patients with chronic low back pain. J. Health Sci Inst.2011.; 29 (3): 205-208.

11. Berni AD. Technical Research in Economics. Sao Paulo: Saraiva; 2002. 
12. Junior JJS, Nicholas MK, Pimenta AM, Asghari A, Thieme AL, et al. Inability questionnaire validation ROLAND-MORIS for pain in general. Rev. Pain. 2010; 11 (1): 28-36.

13. Bento AAC, Paiva ACS, Siqueira FB. Correlation between disability, pain - Roland Morris, and functional capacity - SF-36 in patients with non-specific chronic low back pain. E-Scientia. 2009;2 (1).

14. Brazil. Resolution 196/96de October 10, 1996. Deals with the guidelines and regulatory standards for research involving human beings. National Health Council, Brasília, DF. 10/0ut/1996.

15. Martins JJ, Albuquerque GL, Nascimento ERP, Barra DCC, Souza WGA, Pacheco WNS, et al. Health education needs of caregivers of elderly people at home. Context text in enferm. 2007 AprilJune; 16 (2): 254-62.

16. Reis LA, Torres GV, Reis LA. Sociodemographic characteristics and health of seniors by an institution of Jequié/BA. Magazine space for health. 2008 Jun; 9 (2): 39-46.

17. Aires M, Paskulin LMG, Morais EP. Functional capacity of older elderly: a comparative study in three regions of Rio Grande do Sul Rev. Latino-Am. Nursing. 2009 Jan/Feb; 18 (1): [07 screens].

18. Brazil. Ministry of Health. Department of Health Care. Department of Programmatic and Strategic Actions. Health care for the elderly and aging person/ Technical Area Health of the Elderly. - Brasilia, 2010

19. Trelha CS, Nakaoski T, Franco SS, Dellaroza MSG, Yamada KN, Cabrera M, Mesas AE, Gaetan CCB, et al. Functional capacity of restricted elderly to the whole home Ruy Virmond Carnascialli, Londrina/PR. Semina: Biological Sciences Saúde.2005 Jan./June; 26 (1): 37-46.

20. Pedrazzi EC, Rodrigues RAP, Schiaveto FV. Morbidity and functional capacity of the elderly. Cienc Nursing health. 2007 Oct/ten: 6 (4): 407-413.

21. Neri AL. Aging and quality of life in women. In: Neri AL. (Org.). Development and aging. Campinas: Papirus; 2001; 161-200.

22. Inouye K, Pedrazzani ES. Level of education, socioeconomic status and evaluation of some dimensions of quality of life of octogenarians. Rev. Latino-am nursing. 2007 Sep - Oct; 15 (Esp): 742-7.

23. Ponte C. Low Back Pain in primary care: Its relationship with sociodemographic characteristics. Portuguese Journal of General Practice. 2005; 21: 259-267.

24. Silva MC, Fassa ACG, Valle NCJ. Chronic low back pain in an adult population in southern Brazil: prevalence and associated factors. Public Health documents. 2004 Mar/Apr; 20 (2): 377385.

25. Camargos MCS, Rodrigues RN, Machado CJ. Elderly, family and home: A narrative review of living alone. R. bras. Est. pop.2011 Jan./June; 28 (1): 217-230.

26. Pedrazzi EC, Motta TTD, Vendruscolo TRP, Wehbe SCCF, Cruz IR, Rodrigues RAP, et al. Home arrangement of the oldest elderly. 2010 January/Feb; 18 (1): [08 screens].
27. Nunes $M C R$, Ribeiro $R C L$, Rosado LEFPL, Franceschini $S C$, et al. Influence of socio-demographic and epidemiological characteristics on the functional capacity of elderly residents in Uba, Minas Gerais. Rev. Bras. Fisioter. 2009; 13 (5): 376-82.

28. Mann L, Kleinpaul JF, Weber P, Mota PB, Carpes FP, et al. Training efect of Isostretching on chronic low back pain: a case study. Motriz. 2009; 15 (1): 50-60.

29. Abreu AM. Translation and CulturalAdaptation to the Portugueses Language of the Fear Avoidance Beliefs Questionnaire (FABQ) in Chronic Low Back Pain carriers. [Dissertation]. University of Franca; France; 2006.

30. Kovacs F M, et al. Correlation Between Pain, Disability and Quality of live in Patients with Common Low Back Pain. Spine. 2004; 29 (20): 206-210.
Publish in International Archives of Medicine

International Archives of Medicine is an open access journal publishing articles encompassing all aspects of medical science and clinical practice. IAM is considered a megajournal with independent sections on all areas of medicine. IAM is a really international journal with authors and board members from all around the world. The journal is widely indexed and classified Q1 in category Medicine. 